\title{
A REVIEW OF INFANTILE ACRODYNIA ('PINK DISEASE')
}

\author{
BY \\ DUNCAN LEYS \\ From the Children's Department, Farnborough Hospital, Kent
}

(Received for Publication November 30, 1949)

Selter (1903, 1927), who first described the syndrome of infantile acrodynia clearly, had by 1927 recognized that the apparently incoherent multitude of functional disturbances could be satisfactorily explained as due to autonomic dysfunction, and used the term vegetative neurosis. A groping towards causation has only been possible by a process of exclusion. The concept of diet deficiency, for example, has been abandoned, attractive as it seemed at one time, partly because the disease, whether in symptoms or pathology, resembles no known deficiency disease in man, and partly because it is found very frequently in conditions which seem to preclude malnutrition. The limits of age within which authentic cases have been reported are from the third week (Wyllie and Stern, 1931) to the fourth year; above this age there are probably a few cases which would be recognized by paediatricians or neurologists as falling within the descriptive category, but none of the cases described in later childhood reproduce the typical picture of infantile acrodynia, and the very rare cases reported in adults (White, 1926) rest on insecure evidence. This is not to say that it is impossible for the disease to occur at other ages with a rather different appearance; indeed it is unlikely that a disease which appears not to have its origins in prenatal life or birth itself should be confined to the first four years.

The symptoms of acrodynia as they appear to the physician may be grouped roughly as follows:

Cardiovascular. Tachycardia, hypertension ; occasionally epistaxis, melaena, gangrene.

Emotional. Depression, apathy, fretfulness, perversion of appetite, loss of interest, insomnia.

Nervous System. Myasthenia, hypotonia, photophobia; sweating, incontinence; head-banging, rocking and salaaming; paraesthesia, possibly 'thalamic' pain; disturbed temperature regulation; occasionally tremor, convulsions.

SKIN AND MUCOSAE. Erythema, swelling of hands and feet; ulceration of mouth, loosening of teeth; dystrophy of nails and hair.

Metabolic. Hyperglycaemia, glycosuria; loss of weight; increased basal metabolic rate; enlargement of liver.

ENDOCRINE. Cessation of growth; diuresis.

Digestrve. Vomiting, diarrhoea; occasional prolapse of rectum; occasional intestinal spasm, rarely progressing to intussusception.

BLOOD. Neutrophil leucocytosis.

I have records of 31 personal cases, the youngest being 4 months, the oldest 3 years at the onset. The age distribution is shown in Fig. 1. The sexes

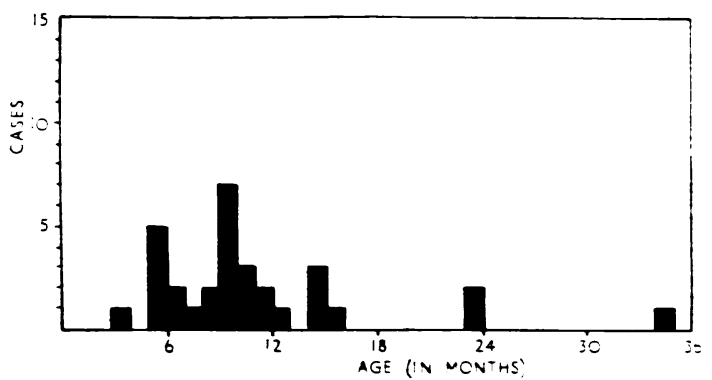

Fig. 1. Age distribution of 31 cases of acrodynia

are equally affected in this group, as in other analysed series (Logan, 1949).

There have been many good descriptions of the symptoms, so it is unnecessary to recapitulate them, but it is worth while to emphasize some of the features. The earliest are emotional: a lively baby becomes increasingly apathetic, loses interest in its surroundings, ceases to play, sleeps little, cries a lot. Older children cease to stand or walk or talk, and do not resume their progress in activity until the illness is past. No smile can be provoked, and the child resents being lifted or handled unless to be nursed very quietly. The earliest symptom of recovery is an improvement in mood and interest.

Sweating is not invariable, but is sometimes excessive and prolonged. The only one of my cases to have obviously severe colic was the oldest, a child of 3 years, but one suspects that colic is not 
uncommon. The temperature is usually raised (invariably in my cases), but occasionally subnormal (Feer, 1935). The hypotonia is profound; a tentative diagnosis of myotonia congenita had been made in one of my cases, and no other disease produces such severe generalized loss of tone. But although immobility in the characteristic flexion position (occasionally opisthotonic) is preserved for hours without true sleep, the child will struggle on occasion and actual paralysis is never present. Tendon jerks were preserved in all but one of my cases. Tremor and convulsions have been described, and also facial palsy (Wyllie and Stern, 1931), but I have not seen either.

A heart rate of 120 to 140 (much higher rates occur) is such a constant feature that one would hesitate to diagnose in the absence of tachycardia. The raised blood pressure is another useful diagnostic point. Bowman (1933) found the normal neonatal pressure to be 64/44. Allen-Williams (1945) made it $90 / 60$ in the second half of the first year, rising to $100 / 65$ at the end of the year. I have reasonably accurate measurements in 18 cases as follows:

$\begin{array}{lcccccccc}\text { Maximum systolic } & \text { pressure: } & 110 & 100 & 90 & 80 \\ \text { Cases: } & 1 & 1 & 4 & 4 & 1 & 2 & 4 & 1\end{array}$

Judging by the way in which some of the children rub their hands and feet, paraesthesia must be severe, but the skin is not necessarily hypersensitive; indeed some children seem to like to be stroked or rubbed, and it is probably for the sake of coolness rather than to escape pressure from the bedclothes that they crawl out from under them. Both appearance and symptoms in hands and feet are at times reminiscent of erythromelalgia. Movement of the joints is sometimes resented. Gareau (1942) considers lymphadenopathy common.

The rash varies: it is more obvious in older children, and in young babies is more or less limited to the hands and feet, which are swollen but do not pit on pressure. The colour of the hands and feet may be normal, red, or cyanotic. A three-year-old child had swellings in various parts of the body (elbow, forehead, legs) and purpura. The usual rash is erythematous, persistent or recurrent, macular or confluent, and some desquamation is invariable. The rash may appear early, or not until other symptoms have been present for some weeks.

Two of my cases lost some of their teeth, and one of these had atrophy of the nails and lost his scalp hair. Gangrene has been described (Weber, 1922; Feer, 1935; Rocaz, 1936). This group of symptoms is probably to be ascribed to ischaemia from vasospasm. Stomatitis and gingivitis are secondary phenomena.
Functional Pathology

No other disease is described, at any age, in which such perverted function of the vegetative nervous system is seen as a clear picture, with the possible exception of hyperthyroidism. In the latter condition, however, it is the orthosympathetic alone which is disturbed, whereas in acrodynia the symptoms can only be explained by a disturbance of the whole autonomic system. It is impossible, and unnecessary, to suppose that this disturbance is peripheral; there is only one site in the body which can be regarded as regulating the autonomic in such a way as to cause such disorganization when it is itself the site of a pathological process, and this is the diencephalon. It would not in fact be inappropriate to speak of acrodynia as 'diencephalopathy.'

All the primary features of acrodynia have been described as following local disease processes or experimental interference with the hypothalamus. The form of this region of the brain undergoes important changes during growth, assuming a position in the economy of the nervous system which is decreasingly important as adult life is reached. It would perhaps be better to say that in adult life the part the hypothalamus plays in the behaviour of the whole organism is less in evidence, overlaid by systems of later functional development. Anatomically, it is a more complex structure in the embryo than in the adult and represents an extension of olfactory function, concerned with emotional life. Grinker (1944), who regards the hypothalamus not as having a multitude of functions spatially separated in terms of cell groups (an almost impossible conception in relation to its size), but as a balancing mechanism, believes that there are nevertheless two general systems contained within it, acting reciprocally, the posterior orthosympathetic and the anterior parasympathetic. He classifies the influence of this regulating mechanism under four heads: (1) endocrine, (2) emotional, (3) awareness or attention, and (4) autonomic, mediated through the pituitary, the vagus, the thalamus, the thoracic sympathetic outflow. The information comes partly from destructive lesions occurring naturally (tumour, encephalitis) and partly from experimental physiology. A monograph by Le Gros Clark, Beattie, Dott, and Riddoch (1938) surveyed this field. The relevant results of proved hypothalamic disturbances are as follows:

ENDOCRINE. (a) Emaciation ; (b) diuresis ; (c) diabetogenic; (d) adrenal cortical depression; (e) arrest of growth.

Emotional. Depression, irritability, lack of emotional expression, possibly ' rage attacks.'

Attention. (a) Hypersomnia, catalepsy, disturbed 
sleep rhythm; (b) apathy, loss of interest, passivity.

Autonomic. (a) Hypertension due to arteriolar contraction; (b) tachycardia; (c) contraction of bladder and intestinal muscle; (d) excessive tears and saliva, sweating; (e) disturbed temperature regulation.

Thus all the symiptoms of infantile acrodynia are comprehended in the effects known to follow abnormal function of the hypothalamus, with the exception of anorexia, hypotonus, photophobia, and the skin lesions. Attacks of tonelessness (kataplexy) are closely associated with hypersomnia; hypothalamic pathology in this condition is unproven, but generally assumed. A 'functional' hypothalamic disturbance as the mechanism of anorexia nervosa has been postulated. The 'erythrooedema' of acrodynia suggests arteriolar spasm ; the photophobia, which is not accompanied by any evidence of an inflammatory condition, is perhaps explained as the result of slow contraction of the pupil to light. Day, Smith, and Klingman (1939) have carried out some experiments which tend to show that the autonomic nervous system is unresponsive to normal stimuli in these children. Cheek and Hicks (1950) have shown in a series of cases that the blood sodium chloride is depleted; their patients improved rapidly when given salt and desoxycorticosterone. They suggest that the salt depletion is due to adrenal failure and that the ' erythro-oedema' is a sign of disturbed water balance.

\section{Epideniology}

There have been many contributors to the literature of this subject whose interest has been roused by groups of cases seen in a relatively short space of time. Bilderback (1946) represents opinion in the United States when he says categorically that this is a sporadic, not an epidemic disease. But he notes that it appears to have a local incidence, being more common in Europe, and especially in Great Britain, than in the U.S.A., tends to occur in the country and in small towns, and agrees that cases are often seen in groups.

\footnotetext{
'It has been the experience of many clinicians that they may see a number of cases of acrodynia within a few months and not observe one again for several years.'
}

Spitz and Wolf (1946) describe under the title ' anaclitic depression' what was almost certainly an outbreak of the disease in a nursery affecting 19 out of 123 children.

Case reports were common and interest widespread in the period 1914-30. Swift (1918) reported a group of 14 cases in Australia in 1914, and this was rapidly followed by descriptions of similar groups, usually of 10 to 12 cases, in various parts of the world. This 'outbreak' seems to have died down about 1925, but in the decade 1935-45 increasingly frequent reports suggested a recrudescence in America. Zahorsky (1937) described 60 cases which he thought were grouped in 'island, fashion (a phenomenon previously described by Péhu and Boucomont 1936), and was considered due not only to geographical but to racial causes, since in his group he found no Jewish patients, although more than a third of his practice was among Jews. This might equally well have been due, however, to differences in custom or diet. A large number of cases were seen and described during the years immediately following the 1914-18 war, and coincided with the influenza epidemic. The relationship of acrodynia as described in the twentieth century, beginning with Selter's account of eight cases in Germany in 1903, to a disease occurring in much more widespread form during the nineteenth century in France (in particular a description of an epidemic in 1830) is too vague to be worth serious consideration, although some authors have considered them related or identical (Craig, 1927). I have not been able to obtain a copy of Chardon's description of this outbreak which is referred to by several writers (Chardon fils, 1830), but it seems unlikely that the data could be enough to establish it as the same disease. It was apparently estimated that about 50,000 cases occurred in France at this time, and no 'outbreak, of acrodynia with numbers approaching this figure has ever been reported in any other part of the world.

\section{Regional Distribution of Mortality Statistics}

Logan (1949) analyses the death certification of acrodynia in England and Wales from 1923 (when the first case was recognized) to 1947 . By 1926, when there was general appreciation of the diagnosis, there were 20 certified deaths, and thereafter a slow rise in numbers to a peak of 88 in 1936 . The figures for $1937-39$ were $73,81,69$, but fell to a steady level near 50 for $1940-46$, with an abrupt rise to 103 in 1947. Regional analysis for the years 1940-46 shows a general tendency (which is statistically significant) for more cases to occur in the north than the south, with the lowest incidence in south-west England.

\section{Seasonal Incidence}

The disease is generally thought to appear more commonly in the spring and summer. The main incidence has been considered by Blackfan and McKhann (1933) to be February to June, by 
Braithwaite (1933) March to October, by Groom (1941) January to June, and by Selter (1927) January to May.

The seasonal onset of my 31 cases is shown in the table. In this group, spring and early summer show most cases, but it is perhaps significant that the cases seen in south England show this clearly, whereas the Scottish cases are more nearly distributed throughout the year.

In the period 1939-45, I observed 16 cases in the Highlands of Scotland. My position was exceptional in that $I$ was the only consulting physician working in this relatively isolated area, and although I am not confident that all cases in the Highlands, even perhaps grave ones, came to my notice, I believe it to be unlikely that many were missed. The distribution of these cases corresponded roughly to the population density of the whole region; they were not concentrated in the towns. The time sequence, however, may be of significance; this is a condition which has interested me for more than 20 years, but in the period 1931-38, working in a Midlands industrial area with a large children's clinic and with the charge of 20 paediatric beds, I saw only three or four cases. In 30 months' paediatric practice in Kent, with patients drawn mainly from the densely populated outer suburbs of London, I have seen 15 cases. The distribution in years is shown in Fig. 2.

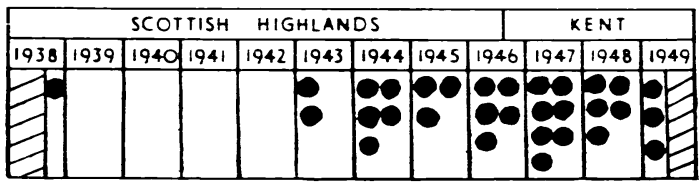

Fig. 2. Distribution in years of 31 personal cases of acrodynia.

From the published data, one must conclude that nothing approaching an epidemic has been reported, but the case incidence is certainly compatible with an infective or toxic cause with periodic enhancement of risk and widespread immunity.

\section{Infection}

Contact cases are unknown. Attempts to obtain evidence of the infective nature of the illness have been made through examination of the spinal fluid, which is rarely found to be pathological by the methods of analysis in current use. Occasionally a slight increase in protein or cells has been recorded early in the disease (Rocaz, 1933; Blackfan and McKhann, 1933). Five of my cases showed completely normal cerebrospinal fluids at the time of diagnosis. Many observers have believed a virus infection to be likely (Cobb, 1933), and others have thought that preceding bacterial infection was frequent (Rodda, 1925). It was mentioned in only four of my cases.

More than One Case in a Family. This has been reported so often as to be recognized as a common feature of any considerable series of cases (Wood and Wood, 1935; Clements, 1940; Gareau, 1942; Kniper, 1927). Two of my cases belonged to one family; the second child developed the disease more than four years after the first and was not born until after the first had fully recovered.

\section{Morbid Anatomy}

This is particularly difficult ground. The protracted illness, with emaciation, gives obvious opportunity for secondary infection, and in most of the reported necropsied cases bronchopneumonia was present. This has been thought by many to invalidate the supposed specificity of the morbid histology reported, especially in the spinal cord. The term 'erythro-oedema-polyneuritica' has been used fairly widely to describe the condition, a name based partly on the evidence of peripheral neuritis found at necropsy. Paterson and Greenfield (1923) described demyelinization, especially of the smaller fibrils in limb nerves, lymphocytic infiltration, and chromatolysis of anterior horn cells. One of their cases which showed the most striking changes of this type had died of miliary tuberculosis. It is not possible at present to state what constitutes a nonspecific, toxic or allergic change in the histology of the nervous system, and others have not been able to confirm the findings of demyelinization in the peripheral nerves. No changes considered at all specific were found by Wyllie and Stern (1931) in seven necropsies, or by Blackfan and McKhann in five. Orton and Bender (1931) reported degeneration of lateral horn cells which they considered to be the effector cells of the splanchnic sympathetic; they were impressed by the clinical and pathological resemblances between cases of actodynia and pellagra.

Francioni and Vigi (1928) described the syndrome of acrodynia appearing in a child convalescent from what they believed to have been epidemic encephalitis; this child, four years old, died of the disease and they discovered degenerative changes in the infundibulum and tuber cinereum. Cobb (1933) in a critical review of these findings, was inclined to accept those described by Orton and Bender and by Francioni and Vigi, but to reject those of Paterson and Wyllie as nonspecific. Warthin (1926) found no evidence of polyneuritis, but spinal cord changes which he also thought to resemble closely those of pellagra. Both of his subjects died of pneumonia. Bilderback (1946) considers that 
published reports give no good evidence of specific changes at all and remarks that an 'organic' disease with such constant clinical phenomena would certainly be expected to produce definite histological changes. A necropsy on one of his cases is reported in detail, with the conclusion that nothing was seen which might not also have been observed as a result of any long exhausting illness.

It is clear that the number and range of observations are far too limited for any conclusions to be drawn; it is doubtful whether purely histological study, at least by existing techniques, will correct this deficiency, but clearly important that attempts should be made. The clinical evidence suggesting somatic neuropathy is slight and in view of the facts pointing to disturbed hypothalamic function, it would seem that attention should be concentrated on the diencephalon.

\section{Nutrition}

The evidence for regarding acrodynia as wholly or partly due to nutritional defect rested first on the resemblance of acrodynia to some types of vitamin $B$ deficiency, and secondly on the supposed similarity of the spinal cord histology in acrodynia and pellagra. Anorexia, polyneuritis, apathy, and depression are features of both thiamine and nicotinic acid deficiency; hypotonia and photophobia have been described in ariboflavinosis. There are at least superficial resemblances between the chronic dermatitis of pellagra and the exfoliative stage of acrodynia. Orton and Bender (1931), who described destructive lesions in the lateral horn cells in a fatal case of acrodynia, considered them almost identical with those found in adult cases of pellagra in which severe anorexia, psychosis, dermatitis, diarrhoea, peripheral neuropathy and trophic lesions had been present. Warthin (1926) was of the same opinion. But many of the symptoms of vitamin B deficiency are lacking; there are no lesions of the tongue or cheilosis, the photophobia is not associated with other changes in the eye, and clinical signs of peripheral neuritis are slight or absent.

The nutritional history of most cases is above suspicion; the disease has often developed in children who were entirely breast-fed by mothers in good health. Further, therapeutic tests should by now have put the matter beyond doubt, and these have been on the whole negative. Many physicians claim improvement by using thiamine, but their tests have not been well controlled. Tisdall, Drake, and Brown (1938) used nicotinic acid without evidence of improvement. Forsyth (1941) thought he obtained some benefit from wheat germ, but none from yeast extracts, and suggests vitamin $E$ deficiency as the cause. The rather abrupt onset of symptoms is against a dietetic cause, and there are many features of the disease which bear no relation to any known diet deficiency syndrome (for example the persistent rise in blood pressure). I have used thiamine, pyridoxine, calcium pantothenate, and riboflavine, without appreciable results.

\section{Poisons}

Some resemblance has been noted between the symptoms of acrodynia and those of rye fungus poisoning (ustilaginism), but the existence of typical cases in wholly breast-fed children makes any theory based upon this untenable. Clements (1940) thought it worth while, however, to carry out some experimental work on mice with rye fungus, with negative results. The disease seen in rats due to ' egg white injury, resulting in biotin deficiency, has also been thought to bear a resemblance to infantile acrodynia (Findlay and Stern, 1929). Recently, it has been suggested that poisoning or idiosyncrasy to mercury may be the fundamental cause. (Warkany and Hubbard, 1948; Bivings and Lewis, 1948; Bivings, 1949.) The idea is not new, since it was apparently considered a possibility by Zahorsky in 1922 . The resemblance to classical mercurial poisoning is slight; many infants are still given mercury by doctors, nurses and mothers, either as 'grey powder' or 'teething powder,' yet acrodynia is an uncommon disease. In cross-examination, mothers of some recent personal cases have denied any such treatment, and there seems no reason to doubt their word. The evidence, in fact, rests upon the microanalysis of the urinary output of mercury. Bivings and Lewis (1948) found $100 \gamma$ of mercury per litre in the urine of a girl of 6 months with acrodynia, and none two weeks later, after she had been treated with BAL (British anti-Lewisite). The disappearance of the mercury coincided with clinical improvement, but the duration of her illness is not stated; residual photophobia was thought to be due to iritis and was cured by atropin. Bivings subsequently collected data on $\mathbf{4 4}$ cases, in $\mathbf{2 8}$ of which mercury had either been administered or found in the urine; in three of the remainder, the urine was free from mercury (Bivings, 1949). The source of the mercury was thought to be teething powder, but mercury ointment and corrosive sublimate had been used locally in other cases. Warkany and Hubbard (1948) considered amounts of over $50 \gamma$ per litre of urine, as determined by their technique of analysis, significant of intoxication. Control cases rarely showed this amount. The maximum found in a case of acrodynia was $360 \gamma$ per litre; no other case showed more than 100. Excretion seemed to be erratic, and was present in some cases for months.

Teething powders had been used in three recent 
cases seen by me; in the urine of one of these, and also in the urine of another case without reliable history, mercury was found in amounts not exceeding $100 \gamma$ per litre; in two further cases, teething powders had been used, but not until after the development of symptoms. Much work will be necessary before the significance of these results can be estimated. They have called attention to the extraordinary prevalence of the use of mercury in infancy and surveys will be required both of the use of teething powders and of the normal incidence of mercury in the urine. With the help of members of the county child health staff in Kent, an enquiry was made of 100 mothers of children aged between 12 and 24 months. Forty-eight of them had used powders containing calomel, and another four had used grey powder. The powders had often been given every week from a very early age. None of these children showed symptoms of acrodynia (Leys, 1949).

The excretion of other trace metals in the urine of children with acrodynia must be determined also, since diuresis is probably a constant feature of acrodynia and there is also serious metabolic derangement. Annual, regional, and seasonal incidences are difficult to reconcile with such a cause. Arsenic has also been incriminated (Calvin and Taylor, 1935).

This overworked word badly needs redefining, but the present state of our knowledge hardly allows of this, and in the meantime we must continue to use it in a descriptive sense. The idea that acrodynia may be regarded as an allergic phenomenon has been held with great tenacity by some observers (Helmick, 1927) and certainly there are many symptoms which suggest the connexion; the rash, which will often continue for weeks, although never frankly urticarial, is not unlike that seen in some types of chronic allergy. Eosinophilia is not seen, nor has anyone produced evidence of the 'allergic constitution.'

\section{Emotional Factors}

I believe the initial symptom in every case to be loss of affect; this, and refusal of food, are the things which most distress parents. The general appearance of the fully declared case is either one of deep depression or of apathy; although the children are often said to be irritable, they are not restless, but passive; fretful crying seems rather a sign of discomfort unrelated to the environment. Many show no sign, beyond a languid movement of the eyes, that they are aware of your approach, and the best efforts to amuse do not bring a smile, or any indication of interest when toys are offered.
The degree of this ' withdrawal' varies in duration and intensity; in the worst cases it continues for months or until death. The advances of the infant's mother often seem no more welcome than those of a stranger. I have seen infants almost in extremis from infection or severe anaemia, who still maintained an active interest in their surroundings. To watch the child with acrodynia is to receive a very deep impression of a primary emotional disorder. Revival of interest is an absolute indication of ultimate recovery, although full health may still not be regained for many months.

Under the title of ' anaclitic depression' Spitz and Wolf (1946) describe a syndrome which occurred among a group of infants in a nursery and foundling hospital; the nursery children were temporarily and the foundlings permanently separated from their mothers. There were 19 cases among 123 infants who were under observation, and at the onset of the syndrome the youngest child was 5 and the oldest 11 months old. The duration of the illness in recovered cases was something over three months, and the authors believed that restoration of the infant to its mother was the signal for improvement. The most serious cases were in children separated from mothers who had been particularly devoted to them. No analysis of mortality.is given, but several of the foundling children died; arrested development in behaviour was noted among all those affected. Spitz and Wolf considered this illness to be comparable to melancholia in the adult and caused by ' withdrawal of the love object.' They compare the refusal of food and susceptibility to infection, which were characteristic of their cases, to suicidal tendencies in the adult, a 'hostile. deprivation taking the place of the destructive power of the superego. In other words, they considered the infants to be suffering from a psychosis, the result of a violent change in environment.

The authors of this paper are psychoanalysts, and seemed to be unaware that these children might be suffering from the condition called for so many years by paediatricians acrodynia, yet their description leaves no doubt of it. The infants ' lost their happy and outgoing behaviour,' refused food, lost weight, showed 'increased susceptibility to colds and eczema' and developed a 'sort of frozen rigidity of expression. They noted a reluctance to touch objects, a preference for lying on the face, bizarre hand and finger movements, a 'stuporous catatonia.' They describe the syndrome and its apparent cure by restoration to the mother or successful substitute for mother-love, in purely psychiatric terms and although in their limited follow-up recovery was apparently complete, they suggest that a distortion of personality of this order 
is likely to leave its permanent mark on development. While the oblivion of these authors to previous clinical description is as regrettable as the ignoring by clinicians of psychiatric implications, their analysis demands a serious consideration of acrodynia as a psychosomatic disease, in spite of some obvious objections, such as differences in regional incidence.

Psychiatrists, as a result of their case analyses and on theoretical grounds, deplore unnecessary admission of young children to institutions. Some physicians have long preached the same gospel as a result of clinical observation; such teaching in fact is acceptable to most children's doctors and experienced children's nurses, who have seen children die in hospital believing (and not on the grounds of risk of infection) that they would have lived had not mother-love, or the best substitute for it, been lacking. We know that the end result of emotional disorder can be death or grave disability from physical disease, as in duodenal haemorrhage, ulcerative colitis, coronary sclerosis. The mechanism may be slow in development. There is, in fact, nothing outrageous in the conception of acrodynia as a primary emotional disorder, and Feer's use of the term 'vegetative neurosis' implies that he had this conception in mind. That psychic trauma in infancy should show itself, lacking the possibility of expression in words or more complex behaviour disorder, as a major disturbance of hypothalamic function, is rather to be expected. Acrodynia, however, is not confined to infants who have been separated from their mothers; on the contrary, 20 of my 31 cases developed in children who were in their mother's care. It so happened that the research undertaken by Spitz and Wolf was concerned with deprived children. If the interpretation of these authors that 'anaclitic depression' is directly caused by physical separation of mother and child is wrong, are there circumstances in sporadic cases from which an equivalent profound emotional disorder could follow ? It is beyond my powers to discuss this question, nor was the possibility in mind when most of my cases were seen. Weaning is noted as immediately preceding the onset in only four cases, and others had developed the syndrome while still at the breast, or had been bottle-fed throughout. The peak age incidence, however, closely follows the weaning age. But if ' mourning' can occur in the infant, its cause may no doubt be much more subtle than the physical removal of the mother or her breast, and to explore such a field may perhaps be as profitable as the estimation of mercury in the urine. In four cases the mother was physically or emotionally ill; the father was absent or dead in five others. I have reliable notes of the order of the family in 24 children, of whom 14 were first-born, eight second, and two third in the family. This distribution does not differ significantly from that of the general population in the last ten years.

\section{Acrodynia-like Syndromes in the Adult}

It would be surprising if any disease process not directly following from prenatal causes or birth trauma, were confined to early childhood. Symptoms, however, are likely to differ, and if no authentic cases of the fully developed syndrome of acrodynia have been recorded in adults, it may yet be worth while to consider whether there are syndromes which recall it. The signs and symptoms in the extremities are reminiscent of erythromelalgia. More suggestive, however, is the condition called neuro-dermato-myositis. This occurs in two forms, acute and chronic; the first is sometimes apparently epidemic (Williams, 1941) but sporadic cases with photophobia occur (Leys, 1942). The chronic form is a grave condition of gradual development leading on to sclerodermia and sometimes to gangrene, and its symptomatology includes acrocyanosis ; acroparaesthesia; tenderness of skin and muscle; sweating; rashes of various types, including urticaria, purpura, erythema, pemphigus and erysipeloid eruptions; salivation; dysphagia ; peripheral oedema; areflexia ; hypotonia and myasthenic paresis ; hypertension ; raised metabolic rate; the Raynaud phenomenon sometimes proceeding to gangrene ; arthropathy ; pigmentation and thickening of the dermis, sometimes proceeding to calcinosis (Sheldon, Young, and Dyke, 1939; Hendry and Anderson, 1939; Dowling and Griffiths, 1939; Dowling, 1939; Thomas, 1942). The aetiology is entirely obscure; the onset may be abrupt or insidious; the illness is of long duration and there is a considerable mortality. Partial syndromes of this type are not very uncommon, and may also appear as a sequel to encephalitis.

\section{Complications, Prognosis and Treatment of Infantile Acrodynia}

The mortality is low; there were no fatal cases in my series of 31 (nor among five further cases seen since this report was compiled), although death rates of up to $30 \%$ have been reported.

These children become emaciated; growth is retarded and there is complete arrest of progress in activity and often considerable regression, e.g. in equilibration. It is generally held that patients are especially prone to develop infections, but this was not a feature in my series; one of my cases had 
definite bronchopneumonia. Many of the patients were treated in hospital, not always in isolation, and not under exceptionally favourable circumstances, in a mixed ward. The physical dangers of treatment in hospital are probably no greater than for other conditions; devoted nursing care is obviously important, and if weight loss can be prevented, the rapidity of recovery is obviously hastened.

Effect of Drugs. Many attempts have been made to influence the course of the disease, or of individual symptoms, by one or other of the many drugs acting upon the autonomic nervous system. Feer (1935) believed that atropine was of general value. Herz (1940) and Day, Smith, and Klingman (1939) both found that tachycardia was increased by it. Herz also had negative results from eserine and from acetyl choline given by iontophoresis. Ergotamine was used without good effect by Nelson (1937) and Feer (1935). Since many of the most unpleasant symptoms appear to be the result of arteriolar constriction, the choline group of drugs, which cause dilatation, would seem to be theoretically the most useful, but have the disadvantage of increasing smooth muscle tone in hollow organs. I have used carbaminocholine in several cases, in doses of 1 to $5 \mathrm{mg}$. orally, or $0.25 \mathrm{mg}$. by injection. The results were difficult to estimate; in two cases, lower pulse rates were seen; in one, this treatment coincided with rather rapid improvement, which was maintained, but was probably the result of the subsidence of the active cause. Looseness of the bowel prevented its continuance in other cases. Prostigmin has seemed to improve muscle tone in a few patients. More recently, I have used small doses of amphetamine because of its good effects in the depression of adults, but have not enough data to report upon its results. The giving of extra salt, as advised by Cheek and Hicks (1950), seems sensible, since salt is lost both by diuresis and by sweating and the intake is reduced; their use of desoxycorticosterone is more debatable. I have had the opportunity of treating one case only in this way; there was a small but definite gain in weight following salt therapy but this was not accelerated by injections of desoxycorticosterone $(1.0 \mathrm{mg}$. on alternate days). The child became more energetic but in the course of a month there was no significant change in the general picture; the dose of sterone, however, was much less than these authors employed.

Some cases have a haemorrhagic tendency, not apparently connected with known vitamin deficiency; epistaxis and purpura of the skin occurred in one of my cases, and melaena in another, severe enough to require transfusion. Relapse is exceptional, but occurred once in this series of 31 cases. Ratcliffe (1941) found no evidence of lasting emotional disturbance in his cases, and this is the general experience; my own follow-up of cases only extends to 18 months, except in one case (five years); none has had any residual symptoms detected.

TABLE

Seasonal Onset of Infantile Acrodynia

\begin{tabular}{|c|c|c|c|c|c|c|c|c|c|c|c|c|c|c|}
\hline Year & & Jan. & Feb. & Mar. & Apr. & May & June & July & Aug. & Sept. & Oct. & Nov. & Dec. & Month \\
\hline 1938 & $\ldots$ & & & & & & & & & & & & 1 & \\
\hline 1943 & . & & 1 & & 1 & & & & & & & & & \\
\hline 1944 & . & & & & & & 2 & 1 & & & 1 & & 1 & \\
\hline 1945 & . & 1 & 1 & & & & & & & & & . & 1 & \\
\hline 1946 & . & & & 3 & & 1 & & 1 & & & & & & \\
\hline 1947 & . & & & & 2 & 2 & 2 & 1 & 1 & & & & & \\
\hline 1948 & . & & & 1 & & 2 & & 1 & & & & & & \\
\hline 1949 & . & & & & & 2 & 1 & & & & & & & \\
\hline Total & . & 1 & 2 & 4 & 3 & 7 & 5 & 4 & 1 & 0 & 1 & 0 & 3 & \\
\hline $\begin{array}{l}\text { Scottish } \\
\text { Highlands }\end{array}$ & . & 1 & 2 & 3 & 1 & 1 & 2 & 2 & 0 & 0 & 1 & 0 & 3 & \\
\hline Kent & $\ldots$ & 0 & 0 & 1 & 2 & 6 & 3 & 2 & 1 & 0 & 0 & 0 & 0 & \\
\hline
\end{tabular}




\section{Summary}

A study of published cases of acrodynia and personal experience of a further 31 , leads to the conclusion that this disease of infancy and early childhood should be regarded as a form of encephalopathy; the complex clinical picture can be satisfactorily explained by disturbed function of the hypothalamus, and the term diencephalopathy is suggested as a convenient descriptive term. The aetiology is still unknown and the possibility is discussed that this may be a primary emotional disorder. Attention is called to symptomatic resemblances between acrodynia in the infant and neuro-dermato-myositis in the adult.

\section{REFERENCES}

Allen-Williams, G. M. (1945). Arch. Dis. Childh., 20, 125.

Bilderback, J. B. (1946). Brenneman's 'Practice of Paediatrics,' Vol. 2, Chap. 20.

Bivings, L. (1949). J. Pediat., 34, 322.

, and Lewis, G. (1948). Ibid., 32, 63.

Blackfan, K. D., and McKhann, C. F. (1933). Ibid., $3,45$.

Bowman, J. E. (1933). Amer. J. Dis. Child., 46, 949.

Braithwaite, J. V. (1933). Arch. Dis. Child., 8, 1.

Calvin, C. V., and Taylor, C. C. (1935). J. Pediat., $6,385$.

Chardon, fils. 1830. Rev. méd. franç. Étrang., 3, 51.

Cheek, D. B., and Hicks, C. S. (1950). Med. J. Aust., $1,107$.

Clements, F. W. (1940). Ibid., 2, 430.

Cobb, C. (1933). Amer. J. Dis. Child., 46, 1076.

Craig, R. A. (1927). Arch. Pediat., 44, 581.

Day, R., Smith, J. R., and Klingman, W. O. (1939). Amer. J. Dis. Child., 57, 269.

Dowling, G. B. (1939). Proc. R. Soc. Med., 32, 256.

-, and Griffiths, W. J. (1939). Lancet, 1, 1424.

Feer, E. (1935). In Pfaundler and Schlossmann's 'Diseases of Children,' ed. Petermann, M. G., Vol. 3, p., $435 . \quad$ Philadelphia.

Findlay, G. M., and Stern, R. O. (1929). Arch. Dis. Childh., 4, 1 .

Forsyth, G. (1941). Med. J. Aust., 1, 78.

Francioni, C., and Vigi, F. (1928). Riv. Sper. Freniat., 52, 307.
Gareau, U. J. (1942). Canad. med. Ass. J., 46, 51.

Grinker, R. R. (1944). Neurology.

Groom, R. J. (1941). Rocky Mtn. med. J., 38, 616.

Helmick, A. G. (1927). Arch. Pediat., 44, 405.

Hendry, A. W., and Anderson, T. E. (1939). Lancet, $1,80$.

Herz, L. F. (1940). Urol. cutan. Rev., 44, 388.

Kniper, T. (1927). Pr. méd., 35, 1075.

Le Gros Clark, W. E., Beattie, J., Riddoch, G., and Dott, N. M. (1938). 'The Hypothalamus.' Edinburgh and London.

Leys, D. (1942). Brit. med. J., 2, 636. (1949). Lancet, 2, 1053.

Logan, W. P. D. (1949). Ibid., 1, 608.

Nelson, R. L. (1937). Arch. Pediat., 54, 300.

Orton, S. T., and Bender, L. (1931). Bull. neurol. Inst. N.Y., 1, 506

Paterson, D., and Greenfield, J. G. (1923). Quart. J. med., 17, 6.

Péhu, M., and Boucomont, J. (1936). J. Méd. Bordeaux, 113, 568.

Ratcliffe, T. A. (1941). J. ment. Sci., 87, 545.

Rocaz, C. (1933). ' Pink Disease,' trans. Wood, I. J. London. (1936). J. Méd. Bordeaux, 113, 157.

Rodda, F. C. (1925). Amer. J. Dis. Child., 30, 224.

Selter, P. (1903). Verhandl. Ges. Kinderheilk. Cassel, $20,45$. (1927). Arch. Kinderheilk., 80, 244.

Sheldon, J. H., Young, F., and Dyke, S. C. (1939). Lancet, 1, 82.

Spitz, R. A., and Wolf, K. M. (1946). Psychoanalytic Study of the Child, 2, 313.

Swift, H. (1918). Lancet, 1, 611.

Thomas, E. W. P. (1942). Ibid., 2, 389.

Thursfield, H., and Paterson, D. H. (1922). Brit. J. Dis. Child., 19, 27.

Tisdall, F. F., Drake, T. G. H., and Brown, A. (1938). J. Pediat., 13, 891 .

Warkany, J., and Hubbard, D. M. (1948). Lancet, 1, 829.

Warthin, A. S. (1926). Arch. Path. Lab. Med., 1, 64.

Weber, F. P. (1922). Brit. J. Child. Dis., 19, 17.

White, C. J. (1926). J. Amer. med. Ass., 87, 1092.

Williams, D. (1941). Quart. J. Med., 10, 283.

Wood, A. J., and Wood, I. (1935). Brit. med. J., 2, 527.

Wyllie, W. G., and Stern, R. O. (1931). Arch. Dis. Childh., 6, 137.

Zahorsky. J. (1937). Arch. Pediat., 54, 56. 